\title{
Antenatal Care Attendance Associated with Anemia among Children (<2y) in Rural Lao Cai, Ha Giang and Lai Chau Province, Vietnam: A Cross Sectional Survey
}

\author{
Matthew Ryan Brown, Nguyen Tu, Huỳnh Nam Phương, Pham Van Phu, Fiona Yeudall, \\ Melody Mendonca, Nguyen Do Huy, and Cecilia Rocha \\ Ryerson University and the National Institution of Vietnam
}

Introduction: In rural, Northern Vietnam, there are concurrent high levels of agricultural production, childhood anemia and malnutrition. The study, "Scaling up local production of fortified foods" attempts to promote food security among women farmers and decrease childhood malnutrition by producing local fortified complimentary foods. Funding was provided by the Canadian International Food Security Fund, the International Development Research Centre and Global Affairs Canada.

Objective: To observe the rate of anemia among children $(<2 y)$ and explore predictor variables among nine rural communes of Lao Cai, Lai Chau and Ha Giang province in Vietnam. This study is part of a larger project, "Scaling up Local Production of Fortified Food" to decrease malnutrition among children and women subsistence farmers in Vietnam.

Methods: A cross-sectional survey was carried out among children $_{(<2 y)}$ in 9 communes $(n=309)$ in the rural northern provinces of $\mathrm{Ha}$ Giang, Lai Chau and Lao Cai in Vietnam. A three-stage sampling method was used and inclusion criteria required communes to be in rural areas with high poverty and malnutrition rates, where subsistence farming is predominant. Capillary blood sampling and visible-spectrometry of cyanmethemoglobin (Shimadzu DAGAIN 02681CD) was performed to assess hemoglobin levels.

Table 1. Logistic Regression Analysis of Factors Associated with Anemia Among Children (<2y) in Lai Chau, Lao Cai and Ha Giang $(n=292)$ in 2016

\begin{tabular}{|l|c|c|c|}
\hline Characteristics & OR & $95 \%$ Cl & P \\
\hline Antenatal Care $_{(\geq 4 \text { visits) }}$ & $0.57^{*}$ & $0.35-0.94$ & .026 \\
\hline $\begin{array}{l}\text { Worse Financially } \\
\text { (than previous year) }\end{array}$ & $1.33^{*}$ & $1.00-1.77$ & .049 \\
\hline Gender $_{\text {(Female) }}$ & 0.64 & $0.40-1.03$ & .067 \\
\hline
\end{tabular}

Prevalence of Anemia with Among Children (<2y) in Lai Chau, Lao Cai and Ha Giang ( $n=292)$ in 2016

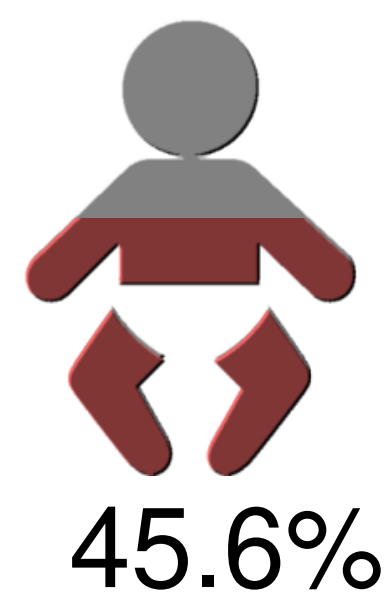

A questionnaire probed associated factors such as; antenatal care visits, nutritional counselling, socio-economic factors, anthropometry of mother-child dyads, household dietary diversity and food security. Associations were explored using a Pearson's $X^{2}$ test and logistics regression analysis for predictors of anemia and linear multivariate analysis for Hemoglobin levels.

Results: The prevalence of anemia among children $(<2 y)$ was $45.6 \%(141 / 309)$ and did not differ significantly between provinces. Logistic regression models showed childhood anemia was lower among mothers who received antenatal care $(\geq 4$ visits) as recommended by the WHO [OR $0.57,95 \% \mathrm{Cl} 0.35$ $0.93, P<0.05]$. It was also lower among families who improved financially compared to the previous year [OR $1.33,95 \% \mathrm{Cl}$ 1.00-1.77, $P<0.05]$. There was a non-significant trend for lower anemia among girls [OR $0.64,95 \% \mathrm{Cl} 0.40-1.03, \mathrm{P}=0.07$ ] but there was a significantly higher level of Hemoglobin found among girls in linear regression models.

Conclusion: These anemia rates classify as a severe public health issue and of specific concern for the neurological development of children ${ }_{(<2 y)}$. Lower rates of anemia were predicted by antenatal ( $\geq 4$ visits) care and if the family had an improved economic situation over the last year. Antenatal care may be an important intervention for anemia prevention in rural provinces in northern Vietnam.

Table 2. Univariate Analysis of Hemoglobin Levels among Children $_{(<2 y)}$ with Associated Factors of Gender, Early Initiation of Breastfeeding and Dietary Diversity in Lai Chau, Lao Cai and Ha Giang $(n=292)$ in 2016.

\begin{tabular}{|l|c|c|c|}
\hline Characteristics & $\boldsymbol{\beta}$ & $\mathbf{9 5 \%} \mathbf{~ C l}$ & $\mathbf{P}$ \\
\hline Gender $_{\text {(Female) }}$ & $0.24^{* *}$ & $0.12-0.35$ & 0.001 \\
\hline Breastfeeding Initiation & $0.13^{*}$ & $0.01-0.24$ & 0.03 \\
\hline AFCS & $0.11^{*}$ & $0.00-0.23$ & $<0.05$ \\
\hline $\begin{array}{c}\text { Worse Financially } \\
\text { (than the previous year) }\end{array}$ & -0.09 & $-2.476-0.34$ & 0.14 \\
\hline
\end{tabular}

\begin{tabular}{|c|c|c|}
\hline Characteristics & $\begin{array}{c}\text { Anemic } \\
(<110 \mathrm{~g} / \mathrm{L} \mathrm{Hb})\end{array}$ & $\begin{array}{l}\text { Non- } \\
\text { Anemic }\end{array}$ \\
\hline ANC4 (Yes) & $43^{*}$ & 73 \\
\hline ANC4 (No) & 91 & 90 \\
\hline Early Initiation BF (Yes) & 83 & 101 \\
\hline (No) & 53 & 57 \\
\hline Gender (Male) & 82 & 81 \\
\hline (Female) & 59 & 88 \\
\hline $\begin{array}{c}\text { Financial Situation } \\
\text { (Better) }\end{array}$ & 20 & 36 \\
\hline (Worse) & 26 & 31 \\
\hline (No Change) & 89 & 98 \\
\hline
\end{tabular}

${ }^{*} \mathrm{P}<0.05$ in two tailed $\mathrm{X}^{2}$ tests 